\title{
Seletividade do clomazone em sementes de algodão tratadas com dietholate e acetato de zinco
}

\author{
Clomazone selectivity in cotton seeds treated with \\ dietholate and zinc acetate
}

\author{
Miriam Hiroko Inoue ${ }^{1 *}$; Natan Ramos Cavalcante ${ }^{2}$; Ronei Ben ${ }^{3}$; \\ Kassio Ferreira Mendes ${ }^{4}$; Ana Cássia Silva Possamai ${ }^{5}$; Rivanildo Dallacort ${ }^{1}$
}

\begin{abstract}
Resumo
O presente trabalho objetivou avaliar a seletividade do herbicida clomazone aplicado em pré-emergência em sementes de algodão tratadas com dietholate e acetato de zinco. Foi adotado o esquema fatorial 4 x 2 (4 métodos de tratamento de sementes e 2 doses de clomazone), distribuído no delineamento de blocos casualizados, com 4 repetições. Nos tratamentos em que foram aplicados dietholate e acetato de zinco, foram utilizadas as doses de $0,4 \mathrm{~kg} \mathrm{ha}^{-1}$ e $8 \mathrm{~mL}$ por $\mathrm{kg}$ de sementes, respectivamente. As doses de clomazone utilizadas referem-se a 0,8 e $1,0 \mathrm{~kg} \mathrm{ha}^{-1}$. A cultivar de algodão utilizada foi a Fiber Max $966 \mathrm{LL}$. Independentemente do tratamento, todas as sementes foram tratadas com o inseticida tiametoxam e o fungicida fludioxonil + metalaxyl-M nas doses de 2,24 e 0,08 + 0,03 g por $\mathrm{kg}$ de sementes, respectivamente, visando o controle de pragas iniciais e dos prejuízos causados por patógenos na germinação e na emergência de plântulas. O tratamento com dietholate e acetato de zinco proporcionou maior vigor inicial às plantas de algodão aos 21,30 e 45 dias após a aplicação. No tratamento com dietholate e acetato de zinco não foi constatado nenhum sintoma de fitointoxicação ao longo das avaliações. As sementes tratadas com dietholate, dietholate e acetato de zinco ou acetato de zinco isoladamente, proporcionaram maior número de capulhos e maior produção de algodão em caroço, em relação à testemunha.
\end{abstract}

Palavras-chave: Fitointoxicação, Gossypium hirsutum, produtividade

\begin{abstract}
The objective of this study objective was to evaluate the selectivity of pre-emergence applications the herbicide clomazone cotton seeds treated with dietholate and zinc acetate. The $4 \times 2$ factorial arrangement was adopted (4 seed treatment methods and 2 clomazone dosages), distributed in a randomized block design with 4 repetitions. In treatments where dietholate and zinc acetate were applied, rates of $0.4 \mathrm{~kg}$ $\mathrm{ha}^{-1}$ and $8 \mathrm{ml}$ per kg of seeds were used respectively. The clomazone rates used refer to 0.8 and $1.0 \mathrm{~kg} \mathrm{ha}$ ${ }^{1}$. The cotton cultivar used was the Fiber Max 966 LL. Independent of treatment, all seeds were treated with tiametoxam insecticide and fludioxonil + metalaxyl-M fungicide at rates of 2.24 and $0.08+0.03 \mathrm{~g}$

\footnotetext{
${ }^{1}$ Profs. Drs., Universidade do Estado de Mato Grosso, UNEMAT, Tangará da Serra, MT. E-mail: miriamhinoue@hotmail.com; rivanildo@unemat.br

${ }^{2}$ Discente do Curso de Mestrado em Genética e Melhoramento de Plantas, UNEMAT, Tangará da Serra, MT. E-mail: natancavalcante2@hotmail.com

${ }^{3}$ Discente do Curso de Mestrado em Agricultura, Universidade Estadual Paulista "Júlio Mesquita Filho", UNESP, Botucatu, SP. E-mail: roneiben@hotmail.com

${ }^{4}$ Discente do Curso de Doutorado em Ciências, Química na Agricultura e no Ambiente, Centro de Energia Nuclear na Agricultura, CENA, Universidade de São Paulo, USP, Piracicaba, SP. E-mail: kassio_mendes_06@hotmail.com

${ }_{5}^{5}$ Discente do Curso de Doutorado em Agronomia, Universidade Estadual de Maringá, UEM, Maringá, PR. E-mail: anacassiapossamai@hotmail.com

* Autor para correspondência
} 
per kg of seed, respectively, to control pests early and limit losses caused by pathogens in germination and seedling emergence. Dietholate and zinc acetate treatment had greater initial effect on cotton plants at 21, 30 and 45 days after application. In phytointoxication symptoms were observed for treatment with dietholate and zinc acetate during the evaluation periods. Seeds treated with dietholate, dietholate and zinc acetate or zinc acetate alone provided a higher number of bolls and seed cotton production compared to the control.

Key words: Phytointoxication, Gossypium hirsutum, productivity

\section{Introdução}

A maior concentração de área cultivada com algodão no Brasil encontra-se nos Estados de Mato Grosso, Goiás e Bahia, com tendência de aumento de área. Neste sentido, estimativas da CONAB (2011) relatam que o índice de produtividade média nacional do algodão em caroço deverá alcançar $3.812 \mathrm{~kg} \mathrm{ha}^{-1}$, contra $3.634 \mathrm{~kg} \mathrm{ha}^{-1}$ obtida na safra passada, representando um incremento médio de $4,9 \%$.

O algodoeiro, como as demais culturas, é influenciado por vários fatores durante o desenvolvimento que pode limitar o seu potencial de produção. Dentre esses, destaca-se a interferência das plantas daninhas que além de aumentar a competição pelos recursos do meio ambiente, principalmente água, luz e nutrientes, influencia negativamente o crescimento, produtividade $\mathrm{e}$ qualidade de fibra (FREITAS et al., 2003).

A convivência do algodoeiro com as plantas daninhas durante todo o ciclo da cultura, pode acarretar prejuízos de até $91,93 \%$ na redução da produtividade (CARDOSO et al., 2010). Contudo, com o intuito de controlar as plantas daninhas, o uso de herbicidas tem se tornado uma prática que tem se expandido em diferentes ambientes de cultivo, sendo um dos métodos mais eficientes e, em muitos casos, o mais econômico (YAMASHITA et al., 2008).

A utilização de herbicidas em pré-emergência e em pós-emergência, é uma ferramenta de manejo muito importante para a cotonicultura da Região Central do Brasil (FREITAS et al., 2006). Contudo, as poucas opções de herbicidas seletivos aplicados em pré-emergência ao algodoeiro para manejo de plantas daninhas, frequentemente, levam a aplicações de herbicidas que resultam em alta toxidez e baixa qualidade de fibra e rendimento do algodão em caroço (SNIPES; SEIFERT, 2003).

O herbicida clomazone, que atua na inibição da biossíntese de carotenoides, pode proporcionar sintomas subsequentes à sua aplicação na cultura do algodoeiro, que variam de injúrias, como amarelecimento ou branqueamento das folhas até diminuição do crescimento, desenvolvimento vegetativo, queda de produtividade e baixa seletividade para a cultura. Para melhorar a seletividade desse herbicida ao algodoeiro, temse utilizado o protetor de sementes dietholate, pois inibe a enzima citocromo P-450 monooxigenase, responsável pela ativação do clomazone (FERHATOGLU; AVDIUSHKO; BARRET, 2005).

Neste sentido, os protetores de plantas ou "safeners" são substâncias usadas com a finalidade de promover a seletividade de herbicidas, por meio da proteção de sementes de espécies cultivadas, evitando injúrias que prejudiquem a emergência e alterem o estande, assim como seu próprio desenvolvimento, sem reduzir a eficiência no controle das plantas daninhas (GALON et al., 2011). De acordo com Karam et al. (2003), o uso do dietholate no tratamento de sementes confere ao algodoeiro tolerância a maiores doses de clomazone.

Aliado a isso a utilização de bioestimulantes, produtos formulados contendo nutrientes e reguladores de crescimento, aumenta a importância na medida em que se busca atingir o potencial produtivo das culturas. A aplicação destes tem sido preconizada através do tratamento de sementes e aplicação foliar (FLOSS; FLOSS, 2007). O acetato 
de zinco desempenha papel importantíssimo por auxiliar na síntese de substâncias que atuam no crescimento e nos sistemas enzimáticos, tornando essencial para a ativação de certas reações metabólicas. Participa da síntese do aminoácido triptofano, precursor do AIA (Ácido Indol Acético), um hormônio do crescimento (FAVARIN; MARINI, 2000). Segundo Taiz e Zeiger (2004) o AIA é a principal auxina, hormônio vegetal relacionado ao crescimento das plantas no que diz respeito à expansão celular.

Diante da grande importância do manejo de plantas daninhas, aliada à carência de informações referentes à seletividade de herbicidas no algodoeiro, o presente trabalho objetivou avaliar o efeito de sementes de algodão tratadas com dietholate e acetato de zinco, com posterior aplicação em préemergência de clomazone.

\section{Material e Métodos}

O experimento foi conduzido na safra 2010/2011 na área experimental da fazenda Paiaguás, localizada na rodovia BR 364, $\mathrm{km} \mathrm{328,} \mathrm{município}$ de Diamantino-MT, com sede nas coordenadas $14^{\circ} 04^{\prime} 25^{\prime \prime}$ latitude sul e $37^{\circ} 26^{\prime} 45^{\prime \prime}$ ' longitude oeste. E foi adotado o esquema fatorial $4 \times 2$, os fatores referem-se aos métodos de tratamento de sementes (testemunha sem aplicação, aplicações de dietholate, dietholate e acetato de zinco, acetato de zinco) e doses de clomazone $\left(0,8\right.$ e $\left.1,0 \mathrm{~kg} \mathrm{ha}^{-1}\right)$, distribuído no delineamento de blocos casualizados com 4 repetições, totalizando 8 tratamentos dispostos em 32 parcelas.

Os tratamentos foram constituídos de testemunha sem aplicação de dietholate e acetato de zinco + clomazone $\left(0,8 \mathrm{~kg} \mathrm{ha}^{-1}\right)(\mathrm{T} 1)$; dietholate + clomazone $\left(0,8 \mathrm{~kg} \mathrm{ha}^{-1}\right)$ (T2); dietholate e acetato de zinco + clomazone $\left(0,8 \mathrm{~kg} \mathrm{ha}^{-1}\right)(\mathrm{T} 3)$; acetato de zinco + clomazone $\left(0,8 \mathrm{~kg} \mathrm{ha}^{-1}\right)(\mathrm{T} 4)$; testemunha sem aplicação de dietholate e acetato de zinco + clomazone $\left(1,0 \mathrm{~kg} \mathrm{ha}{ }^{-1}\right)$ (T5); dietholate + clomazone (1,0 kg ha-1) (T6); dietholate e acetato de zinco + clomazone $\left(1,0 \mathrm{~kg} \mathrm{ha}^{-1}\right)(\mathrm{T} 7)$ e acetato de zinco + clomazone $\left(1,0 \mathrm{~kg} \mathrm{ha}^{-1}\right)(\mathrm{T} 8)$.

Cada parcela foi composta por 12 linhas com $6 \mathrm{~m}$ de comprimento e 5,4 $\mathrm{m}$ de largura. Como área útil da parcela foram consideradas as 6 linhas centrais, desprezando 0,5 m nas extremidades de cada linha. Independente do tratamento, todas as sementes foram tratadas com o inseticida tiametoxam e o fungicida fludioxonil + metalaxyl-M, respectivamente, nas doses de 2,24 e 0,08+0,03 g por $\mathrm{kg}$ de sementes, visando o controle de pragas iniciais e dos prejuízos causados por patógenos na germinação e na emergência de plântulas. Em seguida, de acordo com o tratamento, estas foram tratadas com o protetor de sementes dietholate e ou acetato de zinco, nas doses de $0,4 \mathrm{~kg}$ por $100 \mathrm{~kg}$ de sementes ${ }^{-1}$ e $8 \mathrm{ml}$ por $\mathrm{kg}$ de sementes, respectivamente.

Os tratamentos foram aplicados nas sementes previamente alocadas em sacos plásticos mantidos lacrados, onde foram acrescentadas as doses dos produtos com uma pequena adição de água, com o auxílio de seringas descartáveis e posteriormente agitados vigorosamente até a distribuição homogênea dos produtos sobre as sementes.

O solo foi preparado de maneira convencional, ou seja, uma aração seguida de duas gradagens. Para correção do solo elevou-se o valor da saturação por bases a $60 \%$ na camada de $(0-20 \mathrm{~cm})$ aplicando calcário dolomítico. As características químicas estão descritas na Tabela 1 e a cultivar de algodão utilizada foi a Fiber Max 966 LL. A semeadura da cultura foi realizada em 26 de janeiro de 2011, utilizando uma semeadora com seis linhas de semeadura, espaçadas em 0,45 metros. A densidade de semeadura foi de 10 sementes por metro linear, totalizando uma população 222,2 mil plantas por hectare. A profundidade de semeadura foi de aproximadamente $3,0 \mathrm{~cm}$. Para adubação de plantio utilizou-se as seguintes dosagens: $125 \mathrm{~kg} \mathrm{ha}^{-1} \mathrm{de}$ superfosfato simples, a adubação nitrogenada foi parcelada, parte da dose no plantio (45 $\mathrm{kg} \mathrm{ha}^{-1}$ de 
uréia) e o restante em duas aplicações de cobertura, entre as fases de abotoamento B1 (110 $\mathrm{kg} \mathrm{ha}^{-1} \mathrm{de}$ sulfato de amônio) e florescimento F1 (110 $\mathrm{kg} \mathrm{ha}^{-1}$ de sulfato de amônio) e $80 \mathrm{~kg} \mathrm{ha}^{-1}$ de cloreto de potássio no plantio e o restante parcelado em duas aplicações de $60 \mathrm{~kg} \mathrm{ha}^{-1}$ de cloreto de potássio cada, até o aparecimento da primeira flor.

Tabela 1. Características químicas do solo na área experimental. Diamantino, MT. 2010/2011.

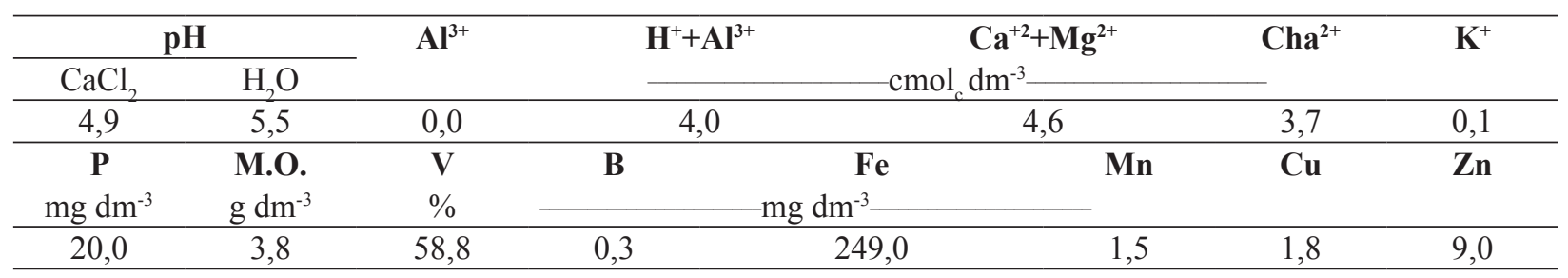

Fonte: Laboratório Agro Análise, Cuiabá, MT.

Logo após o plantio foi efetuada a aplicação do clomazone $\left(0,8\right.$ e 1,0 $\left.\mathrm{kg} \mathrm{ha}^{-1}\right)$ com o auxílio de um pulverizador costal de pressão constante a base de $\mathrm{CO}_{2}$, equipado com 4 pontas XR 110.02, espaçadas em $0,5 \mathrm{~m}$, com pressão de $2 \mathrm{kgf} \mathrm{cm}^{-2}$, proporcionando um volume de calda equivalente a $200 \mathrm{~L} \mathrm{ha}^{-1}$.

Durante o ciclo da cultura, todas as parcelas foram mantidas livres da presença de plantas daninhas por meio de capinas manuais. Todas as demais práticas agronômicas foram feitas seguindose o manejo preconizado na região. As variáveis analisadas foram porcentagem de emergência das plântulas, índice de velocidade de emergência (IVE), estande, vigor inicial do algodoeiro, fitointoxicação, comprimento da raiz e da parte aérea, massa seca da raiz e da parte aérea, teor de clorofila, número de capulhos e produtividade do algodão em caroço.

Nas determinações de porcentagem de emergência e índice de velocidade de emergência (IVE), foram realizadas leituras diárias nas duas linhas centrais de cada parcela, considerando aquelas cujos cotilédones estejam acima da superfície do solo até a estabilização da emergência das mesmas ao sétimo dia (GOULART, 2002). Para o cálculo do IVE foi aplicada a fórmula de Maguire (1962).

$$
\mathrm{IVE}=\mathrm{E}_{1} / \mathrm{N}_{1}+\mathrm{E}_{2} / \mathrm{N}_{2}+\ldots+\mathrm{E}_{\mathrm{n}} / \mathrm{N}_{\mathrm{n}}
$$

Em que:

IVE - Índice de velocidade de emergência.

$\mathrm{E}_{1}, \mathrm{E}_{2} \mathrm{eE}_{\mathrm{n}}$-número de plântulas normais computadas na primeira, segunda e última contagem.

$\mathrm{N}_{1}, \mathrm{~N}_{2}$ e $\mathrm{N}_{\mathrm{n}}$ - número de dias após a implantação do teste.

Para o estande ocorreram avaliações subsequentes aos 21 e 45 dias após a aplicação (DAA) do clomazone, em que foram analisadas as duas linhas centrais de cada parcela, quantificando o número de plantas por metro linear (CRUSCIOL et al., 2002). O vigor inicial foi determinado por meio de avaliações visuais das parcelas aos 21 , 30 e 45 DAA, atribuindo-se notas de 0 a $100 \%$ conforme metodologia adaptada de AOSA (1983). As avaliações de fitointoxicação foram realizadas aos 14, 21 e 30 DAA do clomazone, por meio da observação visual de cada unidade experimental, atribuindo-se notas de 0 a $100 \%$, de modo que nota 0 significa que não foi observado nenhum sintoma e $100 \%$ quando houve a morte total das estruturas vegetais (SBCPD, 1995).

Nas avaliações de comprimento da raiz e parte aérea, foram selecionadas aleatoriamente 10 plantas por parcela aos 21 e 45 DAA. Os comprimentos da parte aérea e das raízes foram determinados com 
auxílio de uma régua graduada em centímetros (ISTA, 1966). Logo depois de realizadas as medições, as plantas foram desidratadas em estufa, a temperatura de $70^{\circ} \mathrm{C}$ durante 48 horas. Após a secagem, foram realizadas as pesagens para determinação da massa seca da parte aérea e das raízes (NAKAGAWA, 1999).

Os teores das clorofilas nas plantas foram quantificados por meio de um medidor eletrônico (clorofilog - modelo CFL 1030) e expressos em unidades denomindas Índice de Clorofila Falker (ICF), aos 21 e 45 DAA. Para tanto, foi coletada a primeira folha plenamente desenvolvida a partir do ápice, sendo amostradas 10 plantas por parcela, totalizando 40 plantas por tratamento, conforme metodologia adaptada de Motomiya (2007).

A avaliação do número de capulhos foi realizada no momento da colheita, por contagem do número de capulhos presente em cada planta nas 3 linhas centrais. A determinação da produtividade foi realizada em material colhido manualmente na área útil da parcela, posteriormente pesados e os dados estimados para $\mathrm{kg} \mathrm{ha} \mathrm{h}^{-1}$ em 13 de julho de 2011.

Os resultados obtidos foram submetidos à análise de variância e às médias comparadas pelo teste de Tukey, a 5\% de probabilidade (SAEG, 1997).

\section{Resultados e Discussão}

A interação tratamento de sementes $\mathrm{x}$ doses foi significativa $(p>0,05)$ para as variáveis vigor inicial de plantas $(21,30$ e 45 DAA), fitointoxicação (21 e 30 DAA), comprimento de raiz (21 DAA), comprimento de parte aérea (21 DAA), massa seca de raiz (21 DAA) e massa seca de parte aérea (21 DAA). Para as demais variáveis emergência, índice de velocidade de emergência, estande (21 e 45 DAA), fitointoxicação (14 DAA), comprimento de raiz (45 DAA), comprimento de parte aérea (45 DAA), massa seca de raiz (45 DAA), massa seca de parte aérea (45 DAA), teor de clorofila (21 e 45 DAA), número de capulhos e produtividade, e foi relatado efeito não significativo $(\mathrm{p}>0,05)$ para a interação tratamento de sementes $\mathrm{x}$ doses.

A porcentagem de emergência e o índice de velocidade de emergência (IVE), após a aplicação de diferentes tratamentos. Ao analisar as médias proporcionadas pelos tratamentos de sementes, os maiores índices de emergência ocorreram no tratamento 1 (testemunha), sendo que as sementes que receberam dietholate e ou acetato de zinco não diferiram entre si para esta variável (Tabela 2).

Contudo, as sementes que receberam a maior dose de clomazone (1,0 $\left.\mathrm{kg} \mathrm{ha}^{-1}\right)$ apresentaram menor porcentagem de emergência e IVE, em relação à dose de $0,8 \mathrm{~kg} \mathrm{ha}^{-1}$. Por outro lado, não houve significância entre os tratamentos de sementes para esta variável (Tabela 2).

Em relação ao estande de plantas aos 21 e 45 DAA, verificou-se que o único tratamento que proporcionou redução no número de plantas foi a testemunha, em ambas as avaliações. Tal fato evidencia que os produtos dietholate e acetato de zinco, aplicados isoladamente ou em mistura, proporcionaram "proteção" às sementes, visto que o estande da testemunha foi afetado pela aplicação de clomazone (Tabela 2). 
Tabela 2. Porcentagem de emergência, índice de velocidade de emergência (IVE) e estande (plântulas $\mathrm{m}^{-1}$ ) do algodoeiro, após a aplicação de diferentes tratamentos. Diamantino, MT. 2010/2011.

\begin{tabular}{|c|c|c|c|c|c|c|}
\hline \multirow{3}{*}{ Tratamentos } & \multicolumn{3}{|c|}{ Emergência (\%) } & \multicolumn{3}{|c|}{ IVE } \\
\hline & \multicolumn{2}{|c|}{ Clomazone $\left(\mathrm{kg} \mathrm{ha}^{-1}\right)$} & \multirow{2}{*}{ Médias } & \multicolumn{2}{|c|}{ Clomazone $\left(\mathrm{kg} \mathrm{ha}^{-1}\right)$} & \multirow{2}{*}{ Médias } \\
\hline & 0,8 & 1,0 & & 0,8 & 1,0 & \\
\hline Testemunha & 98,75 & 97,00 & $97,87 \mathrm{a}$ & 204,68 & 186,10 & 195,39 a \\
\hline Dietholate & 95,75 & 93,25 & $94,50 \mathrm{~b}$ & 203,67 & 187,15 & $195,41 \mathrm{a}$ \\
\hline Dietholate e acetato de zinco & 93,87 & 91,50 & $92,68 \mathrm{~b}$ & 199,19 & 176,09 & $187,64 \mathrm{a}$ \\
\hline Acetato de zinco & 96,62 & 92,62 & $94,62 \mathrm{~b}$ & 225,38 & 194,95 & $210,17 \mathrm{a}$ \\
\hline Médias & $96,25 \mathrm{~A}$ & $93,59 \mathrm{~B}$ & & $208,23 \mathrm{~A}$ & $186,07 \mathrm{~B}$ & \\
\hline \multirow[t]{3}{*}{ C.V. $(\%)$} & \multicolumn{2}{|c|}{2,30} & & \multicolumn{2}{|c|}{10,86} & \\
\hline & \multicolumn{6}{|c|}{ Estande (plântulas $\mathrm{m}^{-1}$ ) } \\
\hline & & $21 \mathrm{DAA}$ & & & 45 DAA & \\
\hline \multirow[t]{2}{*}{ Tratamentos } & \multicolumn{2}{|c|}{ Clomazone $\left(\mathrm{kg} \mathrm{ha}^{-1}\right)$} & \multirow{2}{*}{ Médias } & \multicolumn{2}{|c|}{ Clomazone $\left(\mathrm{kg} \mathrm{ha}^{-1}\right)$} & \multirow{2}{*}{ Médias } \\
\hline & 0,8 & 1,0 & & 0,8 & 1,0 & \\
\hline Testemunha & 4,73 & 5,80 & $5,26 \mathrm{~b}$ & 5,01 & 5,75 & $5,37 \mathrm{~b}$ \\
\hline Dietholate & 8,06 & 8,47 & 8,26 a & 8,00 & 8,36 & $8,18 \mathrm{a}$ \\
\hline Dietholate e acetato de zinco & 8,39 & 9,02 & $8,70 \mathrm{a}$ & 8,28 & 8,06 & 8,17 a \\
\hline Acetato de zinco & 8,09 & 8,06 & $8,07 \mathrm{a}$ & 8,09 & 7,92 & $8,00 \mathrm{a}$ \\
\hline Médias & $7,32 \mathrm{~A}$ & $7,84 \mathrm{~A}$ & & $7,34 \mathrm{~A}$ & $7,52 \mathrm{~A}$ & \\
\hline C.V. $(\%)$ & \multicolumn{2}{|c|}{4,63} & \multicolumn{3}{|c|}{8,06} & \\
\hline
\end{tabular}

Médias seguidas de mesma letra, maiúscula na linha e minúscula na coluna, não diferem entre si pelo teste de Tukey, a 5\% de probabilidade.

Fonte: Elaboração dos autores.

Portanto, apesar das sementes provenientes do tratamento testemunha apresentarem maior porcentagem de emergência em relação aos demais tratamentos, essas não se estabeleceram na mesma proporção das sementes que receberam o tratamento com dietholate e ou acetato de zinco (Tabela 2).

Independente das doses de clomazone, os dados para o estande de plantas, indicam que não houve diferença significativa entre os tratamentos (Tabela 2). Dan et al. (2011) verificaram que o único tratamento que causou redução significativa no número de plantas por metro foi a mistura de clomazone + oxyfluorfen $\left(1,0+0,19 \mathrm{~kg} \mathrm{ha}^{-1}\right)$ provocando uma queda de $8,95 \%$ no número de plantas em relação à testemunha.

A partir dos dados de vigor, observa-se que a adição de dietholate e ou acetato de zinco proporcionou maior vigor de plântulas aos 21, 30 e 45 DAA, em ambas as doses de clomazone (Tabela 3 ).

O herbicida clomazone é considerado seletivo à cultura do algodoeiro, mas é necessário a utilização dos safeners disulfoton e dietholate no tratamento de sementes, visando proporcionar a seletividade do herbicida à cultura (CULPEPPER et al., 2001; PLESE; SILVA; FOLONI, 2009). No que se refere às doses de clomazone, foi possível constatar diferença significativa apenas aos 21 DAA, na testemunha e no tratamento com acetato de zinco, em que a maior dose do clomazone $\left(1,0 \mathrm{~kg} \mathrm{ha}^{-1}\right)$ proporcionou menor vigor as plântulas de algodão, quando comparada a menor dose $\left(0,8 \mathrm{~kg} \mathrm{ha}^{-1}\right)$ (Tabela 3).

$\mathrm{Na}$ primeira avaliação realizada aos 14 DAA, verificou-se que plantas provenientes do tratamento testemunha apresentaram os maiores sintomas de fitointoxicação, em relação às que receberam dietholate e ou acetato de zinco no tratamento de sementes. Nessas plantas, os principais sintomas foram amarelecimento, branqueamento e murcha das folhas, confirmando informações relatadas por Duke et al. (1991). 
Tabela 3. Vigor inicial (\%) das plântulas de algodão, após a aplicação de diferentes tratamentos. Diamantino, MT. 2010/2011.

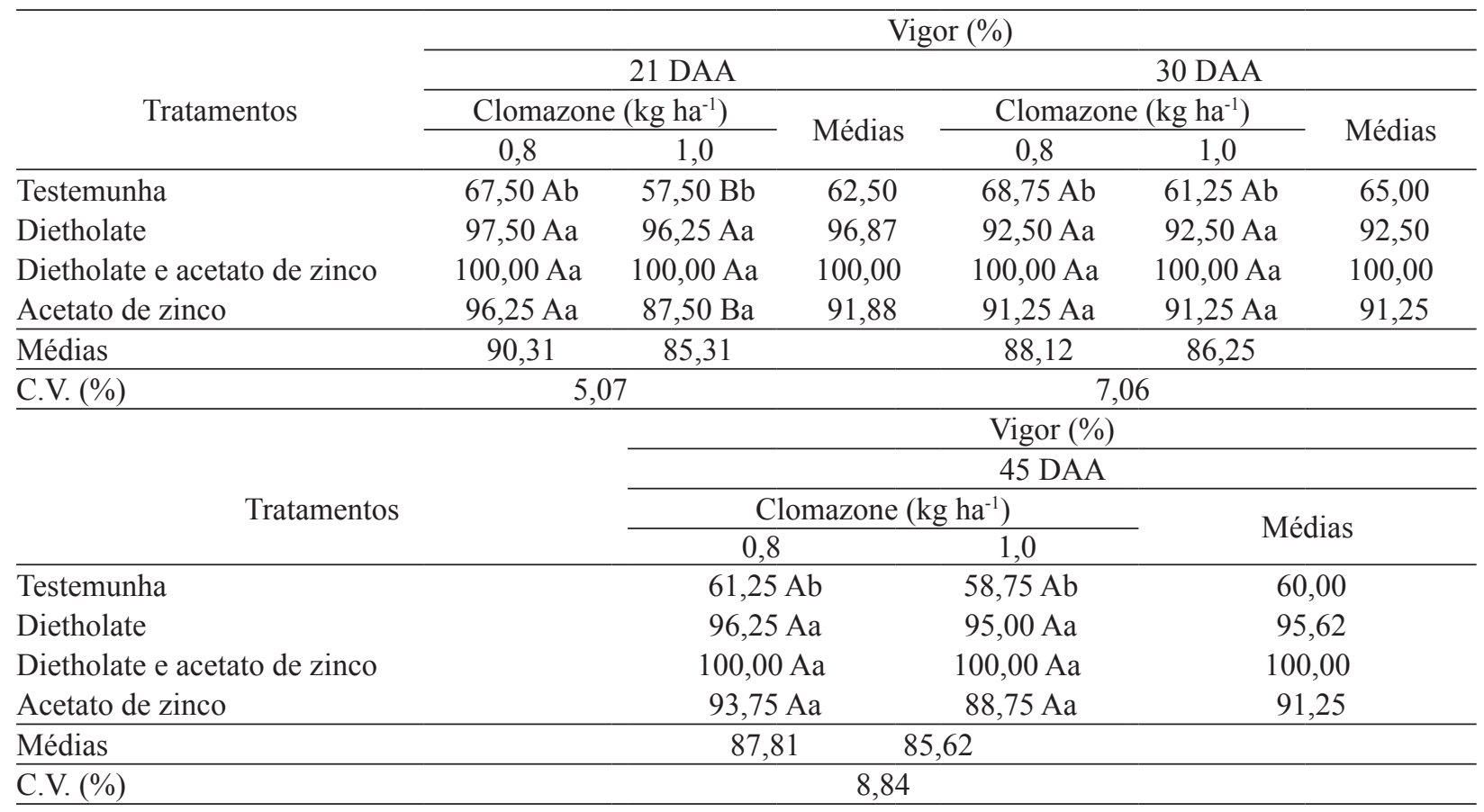

Médias seguidas de mesma letra, maiúscula na linha e minúscula na coluna, não diferem entre si pelo teste de Tukey, a 5\% de probabilidade.

Fonte: Elaboração dos autores.

Constataram-se ainda sintomas leves de fitointoxicação de herbicida nas plantas de algodão proporcionados pelos tratamentos isolados de dietholate e acetato de zinco, mas estes não diferiram significativamente das plantas que receberam a aplicação conjunta de dietholate e acetato de zinco (Tabela 4). Em relação às doses de clomazone, não foi constatada diferença significativa para esta variável.

O dietholate proporciona proteção ao algodão, por meio da inibição da enzima citocromo P-450 mono oxigenase, responsável pela ativação do herbicida (FERHATOGLU; AVDIUSHKO; BARRET, 2005). Com a inibição dessa enzima, não há ativação do clomazone, não havendo assim formação do herbicida ativo e, consequentemente, dano à planta (SANCHOTENE et al., 2010). No caso de plantas tratadas com acetato de zinco apresentar baixos sintomas de fitointoxicação está relacionada com a atuação do Zinco (Zn) na detoxicação celular, na formação e manutenção da integridade da membrana, parede celular e na regulação e atividade hormonal (MALAVOLTA; VITTI; OLIVEIRA, 1997).

Nas avaliações realizadas aos 21 e 30 DAA, observou-se também que apenas plantas da testemunha apresentavam sintomas de fitointoxicação provocada pelo herbicida, sendo que os demais tratamentos proporcionaram proteção às plantas (Tabela 4). Estudos conduzidos por Yazbek Júnior e Foloni (2004) demonstraram que a dose de $0,5 \mathrm{~kg}$ de dietholate para $100 \mathrm{~kg}$ de sementes reduziu os níveis de fitointoxicação do clomazone e proporcionou excelente grau de proteção. Semelhantemente, York e Jordan (1992) observaram que a aplicação dos inseticidas aldicarb, forate e disulfuton reduziram a fitointoxicação de herbicidas na cultura do algodão, conferindo proteção às sementes da cultura. 
Tabela 4. Porcentagem de fitointoxicação, após a aplicação de diferentes tratamentos. Diamantino, MT. 2010/2011.

\begin{tabular}{|c|c|c|c|c|c|c|}
\hline \multirow{4}{*}{ Tratamentos } & \multicolumn{6}{|c|}{ Fitointoxicação (\%) } \\
\hline & \multicolumn{3}{|c|}{$14 \mathrm{DAA}$} & \multicolumn{3}{|c|}{$21 \mathrm{DAA}$} \\
\hline & \multicolumn{2}{|c|}{ Clomazone $\left(\mathrm{kg} \mathrm{ha}^{-1}\right)$} & \multirow{2}{*}{ Médias } & \multicolumn{2}{|c|}{ Clomazone $\left(\mathrm{kg} \mathrm{ha}^{-1}\right)$} & \multirow{2}{*}{ Médias } \\
\hline & 0,8 & 1,0 & & 0,8 & 1,0 & \\
\hline Testemunha & 6,25 & 8,75 & $7,50 \mathrm{a}$ & $2,75 \mathrm{Ba}$ & $8,75 \mathrm{Aa}$ & 5,75 \\
\hline Dietholate & 0,75 & 1,50 & $1,12 \mathrm{~b}$ & $0,00 \mathrm{Ab}$ & $0,00 \mathrm{Ab}$ & 0,00 \\
\hline Dietholate e acetato de zinco & 0,00 & 0,00 & $0,00 \mathrm{~b}$ & $0,00 \mathrm{Ab}$ & $0,00 \mathrm{Ab}$ & 0,00 \\
\hline Acetato de zinco & 1,00 & 1,50 & $1,25 \mathrm{~b}$ & $0,25 \mathrm{Ab}$ & $1,00 \mathrm{Ab}$ & 0,62 \\
\hline Médias & $2,00 \mathrm{~A}$ & $2,93 \mathrm{~A}$ & & 0,75 & 2,43 & \\
\hline C.V. $(\%)$ & \multicolumn{2}{|c|}{65,23} & & \multicolumn{2}{|c|}{79,21} & \\
\hline & & \multicolumn{5}{|c|}{ Fitointoxicação (\%) } \\
\hline & & \multicolumn{5}{|c|}{$30 \mathrm{DAA}$} \\
\hline \multirow[t]{2}{*}{ Tratamentos } & & \multicolumn{3}{|c|}{ Clomazone $\left(\mathrm{kg} \mathrm{ha}^{-1}\right)$} & \multirow{2}{*}{\multicolumn{2}{|c|}{ Médias }} \\
\hline & & \multicolumn{2}{|c|}{0,8} & 1,0 & & \\
\hline Testemunha & & \multicolumn{2}{|c|}{$2,25 \mathrm{Ba}$} & $5,00 \mathrm{Aa}$ & \multicolumn{2}{|c|}{3,62} \\
\hline Dietholate & & \multicolumn{2}{|c|}{$0,00 \mathrm{Ab}$} & $0,00 \mathrm{Ab}$ & \multicolumn{2}{|c|}{0,00} \\
\hline Dietholate e acetato de zinco & & \multicolumn{2}{|c|}{$0,00 \mathrm{Ab}$} & $0,00 \mathrm{Ab}$ & \multicolumn{2}{|c|}{0,00} \\
\hline Acetato de zinco & & \multicolumn{2}{|c|}{$0,00 \mathrm{Ab}$} & $0,00 \mathrm{Ab}$ & \multicolumn{2}{|c|}{0,00} \\
\hline Médias & & & & 1,25 & \\
\hline C.V. $(\%)$ & \multicolumn{6}{|c|}{58,51} \\
\hline
\end{tabular}

Médias seguidas de mesma letra, maiúscula na linha e minúscula na coluna, não diferem entre si pelo teste de Tukey, a 5\% de probabilidade.

Fonte: Elaboração dos autores.

Para variável comprimento das raízes de algodão, não houve diferença significativa entre os tratamentos com a aplicação de $0,8 \mathrm{~kg} \mathrm{ha}^{-1}$ de clomazone aos 21 DAA. No entanto, na dose de $1,0 \mathrm{~kg} \mathrm{ha}^{-1}$, as plantas provenientes do tratamento com dietholate aasociado ao acetato de zinco apresentaram maiores valores em relação à testemunha e dietholate isoladamente. $\mathrm{O}$ tratamento com acetato de zinco também proporcionou comprimento de raiz significativamente superior à testemunha (Tabela 5).

$\mathrm{Na}$ avaliação realizada aos 45 DAA, as médias indicam que o tratamento com dietholate associado ao acetato de zinco proporcionou maior desenvolvimento das raízes de algodão, em relação à testemunha sem aplicação. Contudo, não diferiu dos tratamentos com dietholate ou acetato de zinco isoladamente nesta data de avaliação (Tabela 5). Guimarães, Hrycyk e Mendonça (2007) observaram que o comprimento das raízes de algodão foi prejudicado pela aplicação do herbicida alachlor, provocando redução média de $46,9 \%$ para raiz principal e 34,6\% para a maior raiz secundária, em relação ao tratamento sem o produto.

O comprimento da parte aérea não foi alterado em função de doses e tratamento de sementes aos 21 DAA. Tal constatação deve-se provavelmente ao fato das plantas ainda estarem em início de desenvolvimento apresentando pequeno porte, o que não proporcionou ainda a diferenciação entre os tratamentos para esta variável. No entanto, quando avaliado as médias das doses de clomazone aos 45 DAA, foi possível verificar que as plantas provenientes dos tratamentos que receberam dietholate e ou acetato de zinco apresentaram os maiores comprimentos de parte aérea, em relação à testemunha. Em contrariedade, trabalhos conduzidos por Castro et al. (2008) não indicaram efeitos no comprimento de parte aérea e radicular de soja, quando houve a aplicação de bioestimulante via tratamentos de sementes. 
Tabela 5. Comprimento $(\mathrm{cm})$ da raiz e parte aérea de plântulas de algodão, após a aplicação de diferentes tratamentos. Diamantino, MT. 2010/2011.

\begin{tabular}{|c|c|c|c|c|c|c|}
\hline \multirow{4}{*}{ Tratamentos } & \multicolumn{6}{|c|}{ Comprimento da raiz $(\mathrm{cm})$} \\
\hline & \multicolumn{3}{|c|}{$21 \mathrm{DAA}$} & \multicolumn{3}{|c|}{$45 \mathrm{DAA}$} \\
\hline & \multicolumn{2}{|c|}{ clomazone $\left(\mathrm{kg} \mathrm{ha}^{-1}\right)$} & \multirow{2}{*}{ Médias } & \multicolumn{2}{|c|}{ clomazone $\left(\mathrm{kg} \mathrm{ha}^{-1}\right)$} & \multirow{2}{*}{ Médias } \\
\hline & 0,8 & 1,0 & & 0,8 & 1,0 & \\
\hline Testemunha & $8,44 \mathrm{Aa}$ & $6,44 \mathrm{Bc}$ & 7,44 & 11,06 & 10,48 & $10,77 \mathrm{~b}$ \\
\hline Dietholate & $10,19 \mathrm{Aa}$ & $8,02 \mathrm{Bb}$ & 9,10 & 12,95 & 12,28 & $12,62 \mathrm{ab}$ \\
\hline Dietholate e acetato de zinco & $8,58 \mathrm{Aa}$ & $10,02 \mathrm{Aa}$ & 9,30 & 13,40 & 12,23 & $12,81 \mathrm{a}$ \\
\hline Acetato de zinco & $9,36 \mathrm{Aa}$ & $8,75 \mathrm{Aab}$ & 9,06 & 12,54 & 11,93 & $12,23 \mathrm{ab}$ \\
\hline Médias & 9,14 & 8,31 & & $12,49 \mathrm{~A}$ & $11,73 \mathrm{~A}$ & \\
\hline \multirow[t]{3}{*}{ C.V. $(\%)$} & \multicolumn{2}{|c|}{11,67} & \multicolumn{4}{|c|}{11,04} \\
\hline & \multicolumn{6}{|c|}{ Comprimento da parte aérea $(\mathrm{cm})$} \\
\hline & \multicolumn{3}{|c|}{$21 \mathrm{DAA}$} & \multicolumn{3}{|c|}{45 DAA } \\
\hline \multirow[t]{2}{*}{ Tratamentos } & \multicolumn{2}{|c|}{ clomazone $\left(\mathrm{kg} \mathrm{ha}^{-1}\right)$} & \multirow{2}{*}{ Médias } & \multicolumn{2}{|c|}{ clomazone $\left(\mathrm{kg} \mathrm{ha}^{-1}\right)$} & \multirow{2}{*}{ Médias } \\
\hline & 0,8 & 1,0 & & 0,8 & 1,0 & \\
\hline Testemunha & $8,26 \mathrm{Aa}$ & $7,72 \mathrm{Aa}$ & 7,99 & 16,20 & 13,50 & $14,85 \mathrm{~b}$ \\
\hline Dietholate & $10,22 \mathrm{Aa}$ & $8,67 \mathrm{Aa}$ & 9,45 & 19,60 & 17,70 & $18,65 \mathrm{a}$ \\
\hline Dietholate e acetato de zinco & $8,10 \mathrm{Aa}$ & $10,79 \mathrm{Aa}$ & 9,44 & 20,06 & 17,23 & $18,65 \mathrm{a}$ \\
\hline Acetato de zinco & $9,63 \mathrm{Aa}$ & $9,08 \mathrm{Aa}$ & 9,35 & 19,51 & 15,43 & $17,47 \mathrm{a}$ \\
\hline Médias & 9,05 & 9,06 & & $18,84 \mathrm{~A}$ & $15,96 \mathrm{~B}$ & \\
\hline C.V. $(\%)$ & \multicolumn{2}{|c|}{9,29} & \multicolumn{3}{|c|}{9,30} & \\
\hline
\end{tabular}

Médias seguidas de mesma letra, maiúscula na linha e minúscula na coluna, não diferem entre si pelo teste de Tukey, a 5\% de probabilidade.

Fonte: Elaboração dos autores.

Os dados de massa seca da raiz indicaram que não houve diferença significativa entre os tratamentos com a aplicação de $0,8 \mathrm{~kg} \mathrm{ha}^{-1}$ de clomazone aos 21 DAA. No entanto, sementes que receberam dietholate associado ao acetato de zinco, dietholate ou acetato de zinco não diferiram entre si, apresentaram maior peso de massa seca da raiz com $1,0 \mathrm{~kg} \mathrm{ha}^{-1}$ do herbicida, em relação à testemunha sem aplicação. Aos 45 DAA, observou-se que as médias dos tratamentos com dietholate e ou acetato de zinco foram estatisticamente superiores à testemunha, independente das doses de clomazone (Tabela 6). Do mesmo modo, Ferreira et al. (2007) observaram maior acúmulo de matéria seca de raízes, em relação à testemunha, quando sementes de milho tratadas com Cellerate $(10 \%$ de Mo e $5 \%$ de $\mathrm{Zn}$ ) na dose de $10 \mathrm{~mL} \mathrm{~kg} \mathrm{sementes}{ }^{-1}$.
Em relação aos dados de massa seca de parte aérea, observou-se que os tratamentos com dietholate e dietholate associado com acetato de zinco foram estatisticamente superiores à testemunha aos 21 DAA, quando aplicada a menor dose de clomazone $\left(0,8 \mathrm{~kg} \mathrm{ha}^{-1}\right)$. Em plantas que receberam a maior dose de clomazone $\left(1,0 \mathrm{~kg} \mathrm{ha}^{-1}\right)$ nesta data, constatouse que somente o tratamento com dietholate com acetato de zinco proporcionou maior massa seca de parte aérea, em relação à testemunha. Em ambas as doses, não houve diferença significativa entre os tratamentos com dietholate, dietholate associado ao acetato de zinco e acetato de zinco isoladamente tantos aos 21 quanto aos 45 DAA (Tabela 6). 
Tabela 6. Massa (g) seca da raiz e da parte aérea, após a aplicação de diferentes tratamentos. Diamantino, MT. 2010/2011.

\begin{tabular}{|c|c|c|c|c|c|c|}
\hline \multirow{4}{*}{ Tratamentos } & \multicolumn{6}{|c|}{ Massa raiz (g) } \\
\hline & \multicolumn{3}{|c|}{$21 \mathrm{DAA}$} & \multicolumn{3}{|c|}{$45 \mathrm{DAA}$} \\
\hline & \multicolumn{2}{|c|}{ Clomazone $\left(\mathrm{kg} \mathrm{ha}^{-1}\right)$} & \multirow{2}{*}{ Médias } & \multicolumn{2}{|c|}{ Clomazone $\left(\mathrm{kg} \mathrm{ha}^{-1}\right)$} & \multirow{2}{*}{ Médias } \\
\hline & 0,8 & 1,0 & & 0,8 & 1,0 & \\
\hline Testemunha & $0,41 \mathrm{Aa}$ & $0,27 \mathrm{Bb}$ & 0,34 & 1,03 & 1,23 & $1,13 \mathrm{~b}$ \\
\hline Dietholate & $0,52 \mathrm{Aa}$ & $0,38 \mathrm{Bab}$ & 0,45 & 1,68 & 1,98 & $1,83 \mathrm{a}$ \\
\hline Dietholate e acetato de zinco & $0,50 \mathrm{Aa}$ & $0,51 \mathrm{Aa}$ & 0,51 & 1,54 & 1,85 & $1,71 \mathrm{a}$ \\
\hline Acetato de zinco & $0,40 \mathrm{Aa}$ & $0,40 \mathrm{Aab}$ & 0,40 & 1,43 & 1,74 & $1,58 \mathrm{a}$ \\
\hline Médias & 0,46 & 0,39 & & $1,42 \mathrm{~A}$ & $1,71 \mathrm{~A}$ & \\
\hline C.V. $(\%)$ & & & & & & \\
\hline \multirow{4}{*}{ Tratamentos } & \multicolumn{6}{|c|}{ Massa parte aérea $(\mathrm{g})$} \\
\hline & & $21 \mathrm{DAA}$ & & & DAA & \\
\hline & \multicolumn{2}{|c|}{ Clomazone $\left(\mathrm{kg} \mathrm{ha}^{-1}\right)$} & \multirow{2}{*}{ Médias } & \multicolumn{2}{|c|}{ Clomazone $\left(\mathrm{kg} \mathrm{ha}^{-1}\right)$} & \multirow{2}{*}{ Médias } \\
\hline & 0,8 & 1,0 & & 0,8 & 1,0 & \\
\hline Testemunha & $2,72 \mathrm{Ab}$ & $2,17 \mathrm{Ab}$ & 2,45 & 10,32 & 13,72 & $12,02 \mathrm{~b}$ \\
\hline Dietholate & $4,00 \mathrm{Aa}$ & $3,10 \mathrm{Aab}$ & 3,55 & 17,42 & 19,80 & $18,61 \mathrm{a}$ \\
\hline Dietholate e acetato de zinco & $3,95 \mathrm{Aa}$ & $4,20 \mathrm{Aa}$ & 4,08 & 18,67 & 22,27 & $20,47 \mathrm{a}$ \\
\hline Acetato de zinco & 3,35 Aab & $3,00 \mathrm{Aab}$ & 3,17 & 17,42 & 20,12 & $18,77 \mathrm{a}$ \\
\hline Médias & 3,51 & 3,12 & & $15,96 \mathrm{~A}$ & $18,98 \mathrm{~A}$ & \\
\hline C.V. $(\%)$ & \multicolumn{2}{|c|}{20,68} & \multicolumn{4}{|c|}{21,47} \\
\hline
\end{tabular}

Médias seguidas de mesma letra, maiúscula na linha e minúscula na coluna, não diferem entre si pelo teste de Tukey, a 5\% de probabilidade.

Fonte: Elaboração dos autores.

Aos 45 DAA observou-se que não houve efeito das doses de clomazone para as médias dos tratamentos, sendo que a adição de dietholate e ou acetato de zinco ao tratamento de sementes proporcionou maior massa seca da parte aérea, em relação à testemunha (Tabela 6). Estudos realizados por Karam et al. (2003) relataram diferenças no acúmulo de matéria seca aérea nas plantas de milho, cujas sementes foram tratadas ou não com dietholate. Essas diferenças foram observadas a partir da aplicação de $2 \mathrm{~kg} \mathrm{ha}^{-1}$ de clomazone, sendo que plantas provenientes de sementes não tratadas com dietholate apresentaram reduções de $90 \%$ no acúmulo da matéria seca aérea quando receberam 4 $\mathrm{kg} \mathrm{ha}^{-1}$ de clomazone.

Em relação ao teor total de clorofila as médias indicam que somente o tratamento com dietholate diferenciou da testemunha aos 21 DAA, mas estas não se diferenciaram significativamente dos tratamentos com dietholate associado ao acetato de zinco e acetato de zinco isoladamente (Tabela 7).
$\mathrm{Na}$ avaliação realizada aos 45 DAA, observouse a recuperação dos teores de clorofila nas plantas provenientes da testemunha e todos os tratamentos de sementes apresentaram médias semelhantes. Em relação às doses de clomazone, não foi observada diferença significativa em ambas as avaliações (Tabela 7). Karam et al. (2003) verificaram que o teor de clorofila em milho foi reduzido em 50\% nas plantas provenientes de sementes não tratadas com dietholate com a aplicação de $0,784 \mathrm{~kg} \mathrm{ha}^{-1}$ de clomazone, enquanto que nas plantas provenientes de sementes tratadas com dietholate essa redução foi obtida apenas com $1,74 \mathrm{~kg} \mathrm{ha}^{-1}$ de clomazone.

As médias dos tratamentos de sementes indicam que plantas provenientes das sementes que receberam dietholate e ou acetato de zinco apresentaram maior número de capulhos, em relação à testemunha. No entanto, não foi verificado efeito de doses de clomazone para número de capulhos e nem para produtividade de algodão em caroço (Tabela 8). 
Tabela 7. Teor de clorofila (ICF) amostrado nas folhas de algodoeiro, após a aplicação de diferentes tratamentos. Diamantino, MT. 2010/2011.

\begin{tabular}{|c|c|c|c|c|c|c|}
\hline \multirow{4}{*}{ Tratamentos } & \multicolumn{6}{|c|}{ Teor clorofila (ICF) } \\
\hline & \multicolumn{3}{|c|}{$21 \mathrm{DAA}$} & \multicolumn{3}{|c|}{$45 \mathrm{DAA}$} \\
\hline & \multicolumn{2}{|c|}{ Clomazone $\left(\mathrm{kg} \mathrm{ha}^{-1}\right)$} & \multirow{2}{*}{ Médias } & \multicolumn{2}{|c|}{ Clomazone $\left(\mathrm{kg} \mathrm{ha}^{-1}\right)$} & \multirow{2}{*}{ Médias } \\
\hline & 0,8 & 1,0 & & 0,8 & 1,0 & \\
\hline Testemunha & 29,36 & 28,28 & $28,82 \mathrm{~b}$ & 34,70 & 34,82 & $34,76 \mathrm{a}$ \\
\hline Dietholate & 31,42 & 31,37 & $31,39 \mathrm{a}$ & 34,96 & 34,15 & $34,55 \mathrm{a}$ \\
\hline Dietholate e acetato de zinco & 30,87 & 30,53 & $30,91 \mathrm{ab}$ & 34,69 & 34,72 & $34,70 \mathrm{a}$ \\
\hline Acetato de zinco & 31,03 & 30,79 & $30,70 \mathrm{ab}$ & 33,93 & 34,56 & $34,25 \mathrm{a}$ \\
\hline Médias & $30,67 \mathrm{~A}$ & $30,24 \mathrm{~A}$ & & $34,57 \mathrm{~A}$ & $34,56 \mathrm{~A}$ & \\
\hline C.V. (\%) & \multicolumn{2}{|c|}{5,89} & \multicolumn{4}{|c|}{3,58} \\
\hline
\end{tabular}

Médias seguidas de mesma letra, maiúscula na linha e minúscula na coluna, não diferem entre si pelo teste de Tukey, a 5\% de probabilidade.

Fonte: Elaboração dos autores.

Tabela 8. Número de capulhos por planta e produtividade $\left(\mathrm{kg} \mathrm{ha}^{-1}\right)$ de algodão em caroço, após a aplicação de diferentes tratamentos. Diamantino, MT. 2010/2011.

\begin{tabular}{|c|c|c|c|c|c|c|}
\hline \multirow{3}{*}{ Tratamentos } & \multicolumn{3}{|c|}{ Capulhos (número planta ${ }^{-1}$ ) } & \multicolumn{2}{|c|}{ Produtividade $\left(\mathrm{kg} \mathrm{ha}^{-1}\right)$} & \multirow{3}{*}{ Médias } \\
\hline & \multicolumn{2}{|c|}{ clomazone $\left(\mathrm{kg} \mathrm{ha}^{-1}\right)$} & \multirow{2}{*}{ Médias } & \multicolumn{2}{|c|}{ clomazone $\left(\mathrm{kg} \mathrm{ha}^{-1}\right)$} & \\
\hline & 0,8 & 1,0 & & 0,8 & 1,0 & \\
\hline Testemunha & 5,67 & 6,74 & $6,20 \mathrm{~b}$ & $1.758,33$ & $1.784,71$ & $1.771,51 \mathrm{c}$ \\
\hline Dietholate & 8,01 & 6,88 & $7,44 \mathrm{a}$ & $2.756,94$ & 2749,99 & $2.753,46 \mathrm{~b}$ \\
\hline Dietholate e acetato de zinco & 7,15 & 7,79 & $7,47 \mathrm{a}$ & $3.016,66$ & $3.013,89$ & $3.015,27 \mathrm{a}$ \\
\hline Acetato de zinco & 7,73 & 7,75 & $7,74 \mathrm{a}$ & $2.805,55$ & $2.920,83$ & $2.863,2 \mathrm{ab}$ \\
\hline Médias & $7,14 \mathrm{~A}$ & $7,29 \mathrm{~A}$ & & $2.584,37 \mathrm{~A}$ & $2.617,35 \mathrm{~A}$ & \\
\hline$\overline{\text { C.V. }(\%)}$ & \multicolumn{2}{|c|}{11,26} & & \multicolumn{2}{|c|}{6,62} & \\
\hline
\end{tabular}

Médias seguidas de mesma letra, maiúscula na linha e minúscula na coluna, não diferem entre si pelo teste de Tukey, a 5\% de probabilidade.

Fonte: Elaboração dos autores.

Dan et al. (2011) verificaram que o clomazone nas doses de (1,0 e 1,25 $\left.\mathrm{kg} \mathrm{ha}^{-1}\right)$, não afetou o número médio de maçãs por plantas de algodão obtido aos 130 DAA. Em contrapartida, quando oxyfluorfen $\left(0,19 \mathrm{~kg} \mathrm{ha}^{-1}\right)$ foi aplicado em associação com clomazone $\left(1,0 \mathrm{~kg} \mathrm{ha}^{-1}\right)$ houve redução significativa do número médio de maçãs por planta, as plantas tratadas com esta mistura tiveram queda de $25,5 \%$ em relação à sua testemunha.

Por outro lado, observou-se que todos os tratamentos de sementes avaliados proporcionaram produtividade superior à testemunha. $\mathrm{O}$ tratamento com dietholate e acetato de zinco destacou-se apresentando produtividade superior ao tratamento somente com dietholate. Contudo, tais tratamentos não diferiram das plantas cujas sementes receberam apenas acetato de zinco no tratamento de sementes (Tabela 8).

\section{Conclusões}

Pode-se inferir que o uso de dietholate, dietholate e acetato de zinco ou acetato de zinco apresentaram potencial de proteção das plantas de algodoeiro dos efeitos fitotóxicos do herbicida clomazone, proporcionando ótimo grau de seletividade.

Nos tratamentos em que houve a aplicação de dietholate, dietholate e acetato de zinco ou acetato 
de zinco no tratamento de sementes, a produtividade de algodão em caroço foi, respectivamente, 55, 70 e $62 \%$ superior ao tratamento que não recebeu estes produtos (testemunha). Diante disto demonstrando o potencial de proteção e produtividade de plantas com o uso do acetato de zinco.

\section{Referências}

ASSOCIATION OF OFFICIAL SEED ANALYSTS - AOSA. Seed vigor testing handbook. East Lansing: AOSA, 1983. 88 p.

CARDOSO, G. D.; ALVES, P. L. C.; BELTRÃO, N. E. M.; VALE, L. S. Períodos de interferência das plantas daninhas em algodoeiro de fibra colorida 'BRS Safira'. Revista Ciência Agronômica, Fortaleza, v. 41, n. 3, p. 456-462, 2010.

CASTRO, G. S. A.; BOGIANI, J. C.; SILVA, M. G.; GAZOLA, E.; ROSOLEM, C. A. Tratamento de sementes de soja com inseticidas e um bioestimulante. Pesquisa Agropecuária Brasileira, Brasília, v. 43, n. 10, p. 1311-1318, 2008.

COMPANHIA NACIONAL DE ABASTECIMENTO CONAB. Acompanhamento de safra brasileira: grãos, sétimo levantamento, abril 2011. Brasília: Conab, 2011. $54 \mathrm{p}$.

CRUSCIOL, C. A. C.; LIMA, E. V.; ANDREOTTI, M.; SCHIOCCHET, M. A. Aplicação tardia de glyphosate e estande e desenvolvimento inicial do arroz em sistemas de cultivo mínimo. Planta Daninha, Viçosa, v. 20, n. 1, p. 45-51, 2002.

CULPEPPER, A. S.; YORK, A. C.; MARTH, J. L.; CORBIN, F. T. Effect of insecticides on clomazone absorption, translocation, and metabolism in cotton. Weed Science, Champaign, v. 49, n. 5, p. 613-616, 2001.

DAN, H. A.; BARROSO, A. L. L.; OLIVEIRA JÚNIOR, R. S.; CONSTANTIN, J.; DAN, L. G. M.; BRAZ, G. B. P.; OLIVEIRA NETO, A. M.; D'AVILA, R. P. Seletividade de clomazone isolado ou em mistura para a cultura do algodoeiro. Planta Daninha, Viçosa, v. 29, n. 3, p. 601-607, 2011.

DUKE, S.O.; LYDON, J.;BECERRIL, J. M.; SHERMAN, T. D.; LEHNEN JÚNIOR, L. P.; MATSUMOTO, H. Protoporphyrinogen oxidase-inhibiting herbicides. Weed Science, Champaign, v. 39, n. 3, p. 465-473, 1991.

FAVARIN, J. L.; MARINI, J. P. Importância dos micronutrientes para a produção de grãos. Rio de Janeiro: Sociedade Nacional de Agricultura, 2000.
Disponível em: <http://www.sna.agr.br/artigos/artitecmicronutrientes.htm $>$. Acesso em: 28 jun. 2014.

FERHATOGLU, Y.; AVDIUSHKO, S.; BARRET, M. The basic for safening of clomazone by phorate insecticide in cotton and inhibitors of cytochrome P450s. Pesticide Biochemistry and Physiology, New York, v. 81, n. 1, p. 59-70, 2005.

FERREIRA, L. A.; OLIVEIRA, J. A.; PINHO, E. V. R. V.; QUEIROZ, D. L. Bioestimulante e fertilizante associados ao tratamento de sementes de milho. Revista Brasileira de Sementes, Pelotas, v. 29, n. 2, p. 80-89, 2007.

FLOSS, E. L.; FLOSS, L. G. Fertilizantes organominerais de última geração: funções fisiológicas e uso na agricultura. Revista Plantio Direto, Passo Fundo, v. 100, n. 4, p. 26-29, 2007. Disponível em: <http://www. plantiodireto.com.br/?body=cont_int\&id $=811>$. Acesso em: 28 jun. 2014.

FREITAS, R. S.; BERGER, P. G.; FERREIRA, L. R.; CARDOSO, A. A.; FREITAS, T. A. S.; SILVA, A. A. Interferência de plantas daninhas na cultura do algodão. Revista Ceres, Viçosa, v. 50, n. 289, p. 367-381, 2003.

FREITAS, R. S.; FERREIRA, L. R.; BERGER, P. G.; SILVA, A. C.; CECON, P. R.; SILVA, M. P. Manejo de plantas daninhas na cultura do algodoeiro com S-metolachlor e trifloxysulfuron-sodium em sistema de plantio convencional. Planta Daninha, Viçosa, v. 24, n. 2, p. 311-318, 2006.

GALON, L.; MACIEL, C. D. G.; AGOSTINETTO, D.; CONCENÇO, G.; MORAES, P. V. D. Seletividade de herbicidas às culturas pelo uso de protetores químicos. Revista Brasileira de Herbicidas, Umuarama, v. 10, n. 3, p. 291-304, 2011.

GOULART, A. C. P. Efeito do tratamento de sementes de algodão com fungicidas no controle do tombamento de plântulas causado por Rhizoctonia solani. Fitopatologia Brasileira, Brasília, v. 27, n. 4, p. 399-402, 2002.

GUIMARÃES, S. C.; HRYCYK, M. F.; MENDONÇA, E. A. F. Efeito de fatores ambientais sobre a seletividade do alachlor ao algodoeiro. Planta Daninha, Viçosa, v. 25, n. 4, p. 813-821, 2007.

INTERNATIONAL SEED TESTING ASSOCIATION - ISTA. International rules for seed testing. Basseldorf, Switzerland: Proc. International Seed Testing Association, v. 31, n. 1, p. 1-52, 1966.

KARAM, D.; CARNEIRO, A. A.; ALBERT, L. H.; CRUZ, M. B.; COSTA, G. T.; MAGALHÃES, P. C. Seletividade da cultura do milho ao herbicida clomazone por meio do uso de dietholate. Revista Brasileira de Milho e Sorgo, Sete Lagoas, v. 2, n. 1, p. 72-79, 2003. 
MAGUIRE, J. D. Speed of germination-aid in selection evaluation for seedling emergence and vigor. Crop Science, Madison, v. 2, n. 2, p. 176-199, 1962.

MALAVOLTA, E.; VITTI, G. S.; OLIVEIRA, S. A. Avaliação do estado nutricional das plantas princípios e aplicações. 2. ed. Piracicaba: Potafós, 1997. 319 p.

MOTOMiYA, A. V. A. Diagnósticos para o gerenciamento localizado da cultura do algodoeiro. 2007. Tese (Doutorado em Agronomia) - Escola Superior de Agricultura Luiz de Queiroz. Universidade de São Paulo, Piracicaba.

NAKAGAWA, J. Testes de vigor baseados no desempenho de plântulas. In: KRZYZANOWSKI, F. C.; VIEIRA, R. D.; FRANÇA NETO, J. B. (Ed.). Vigor de sementes: conceitos e testes. Londrina: ABRATES, 1999. cap.2, p. 1-24.

PLESE, L. P. M.; SILVA, C. L.; FOLONI, L. L. Distribuição nos compartimentos ambientais dos herbicidas utilizados nas culturas de algodão, café e citros. Planta Daninha, Viçosa, v. 27, n. 1, p. 123-132, 2009.

SISTEMA PARA ANÁLISES ESTATÍSTICAS E GENÉTICAS - SAEG. Versão 7.0. Viçosa: Fundação Arthur Bernardes, 1997. $150 \mathrm{p}$.

SANCHOTENE, D. M.; KRUSE, N. D.; AVILA, L. A.; MACHADO, S. L. O.; NICOLODI, G.A.; DORNELLES, S. H. D. Efeito do protetor dietholate na seletividade de clomazone em cultivares de arroz irrigado. Planta Daninha, Viçosa, v. 28, n. 2, p. 339-346, 2010.
SNIPES, C. E.; SEIFERT, S. Influence of malathion timing on cotton (Gosypium hirsutum) response to pyrithiobac. Weed Technology, Lawrence, v. 17, n. 2, p. 266-268, 2003.

SOCIEDADE BRASILEIRA DA CIÊNCIA DAS PLANTAS DANINHAS - SBCPD. Procedimentos para instalação, avaliação e análise de experimentos com herbicidas. Londrina: SBCPD, 1995. 42 p.

TAIZ, L.; ZEIGER, E. Fisiologia vegetal. 3. ed. Porto Alegre: Artmed, 2004, 559 p.

YAMASHITA, O. M.; MENDONÇA, F. S.; ORSI, J. V. N.; RESENDE, D. D.; KAPPES, C.; GUIMARÃES, S.

C. Efeito de doses reduzidas de oxyfluorfen em cultivares de algodoeiro. Planta Daninha, Viçosa, v. 26, n. 4, p. 917-921, 2008.

YAZBEK JÚNIOR, W.; FOLONI, L. L. Efeito de protetores de sementes na seletividade de herbicida na cultura do algodoeiro (Gossypium hirsutum L.). Ecossistema, Campinas, v. 29, n. 1, p. 33-38, 2004.

YORK, A. C.; JORDAN, D. L. Cotton (Gossypium hirsutum) response to clomazone and inseticide combinations. Weed Technology, Lawrence, v. 6, n. 4, p. 796-800, 1992. 
